\title{
PREDICTION OF EARLY PROGNOSIS IN INTRACEREBRAL HEMATOMAS: STICH-2 PROGNOSIS SCORE AGAINST HEMPHILL SCORE
}

\author{
Doğan Dinç ÖGE*, Ethem Murat ARSAVA*, Mehmet Yasir PEKTEZEL*, \\ Özlem KAYIM YILDIZ**, Mehmet Akif TOPÇUOĞLU*
}

\author{
*Hacettepe University Hospitals, Department of Neurology and Neurological Intensive Care Unit, \\ Ankara, TURKEY \\ **Cumhuriyet University Medical Faculty, Department of Neurology, Sivas, TURKEY
}

\begin{abstract}
INTRODUCTION: We compared the prognostic accuracy of STICH prognostic score against Hemphill's original ICH (oICH) score for predicting in-hospital mortality related to intracerebral hematoma (ICH).

METHODS: We performed a retrospective single-center analysis of primary ICH patients admitted in our hospital (n=307). 276 patients were included in the study. For each patient, the STICH prognostic score and oICH were calculated. Survival data was acquired retrospectively and mortality rates associated with each score value was calculated for both methods. ROC curve AUC was used to compare the two scoring systems.

RESULTS: For the oICH, the mean score was 1.4 for the whole group, $2.66 \pm 1.22$ for the deceased and $1.27 \pm 1.12$ for the survivors. For the STICH prognostic score, the mean score was $37.3 \pm 55$ for the whole group, $-21.23 \pm 64.64$ for the deceased and $49.33 \pm 42.0$ for the survivors. Their respective ROC curve AUC values were 0.791 (CI $95 \%$ between 0.735 and 0.839 ) for the oICH and 0.829 for the STICH prognostic score (CI 95\% between 0.781 and 0.870 ).

DISCUSSION and CONCLUSION: Both Hemphill's and STICH-2 prognosis scoring systems have good accuracy in predicting in-hospital mortality related to ICH. The STICH score is mathematically more accurate then oICH, but the difference is negligible in terms of clinical yield.

Keywords: Cerebral, hematoma, hemorrhage, volume, mortality, ROC.
\end{abstract}

\section{INTTRASEREBRAL HEMATOMLARDA ERKEN PROGNOZ TAHMINI: HEMPHILL SKORU'NA KARŞI STICH-2 PROGNOZ SKORU}

\section{ÖZET}

GİRIȘ ve AMAÇ: Bu çalıșmada Hemphill'in orijinal intraserebral hemoraji skoruna (oICH) karșı STICH prognostik skorunun hastanede intraserebral hemoraji nedeniyle ölümü ön görme güçleri karşılaștırılmıştır.

YÖNTEM ve GEREÇLER: Primer intraserebral hemoraji nedeniyle hastanemize başvuran hastalar (n=307) üzerinden tekmerkezli ve retrospektif bir çalıșma düzenlenmiștir. Çalıșmaya 276 hasta dahil edilmiștir. Her hasta için STICH skoru ve oICH skoru hesaplanmıştır. Sağ kalım bilgileri retrospektif olarak toplanmış ve her iki metod için ilgili puana denk gelen mortalite oranları hesaplanmıștır. ROC eğrisi kullanılarak iki sistemin prognostik hassasiyetleri karșılaștırılmıștır.

BULGULAR: oICH skoru için tüm grubun ortalama değeri 1,4; ölenlerin ortalama değeri $2,66 \pm 1,22$ ve sağ kalanların

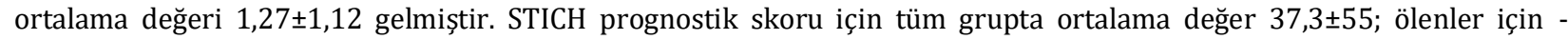
$21,23 \pm 64,64$ ve sağ kalanlar için 49,33 \pm 42 olarak hesaplanmıștır. Orijinal ICH skoru için ROC eğrisinin eğri altındaki alan değeri 0,791 (\%95 Güven Aralığı -GA-: 0,735 ile 0,839 arası), STICH prognostik skorunun ise ROC eğrisi altındaki alan değeri 0,829 (\%95GA: 0,781 ile 0,870 arası) gelmiştir.

TARTIȘMA ve SONUÇ: Hemphill ve STICH-2 prognoz skorlama sistemlerinin her ikisi de hastanede intraserebral hemoraji nedeniyle ölümleri öngörmekte yüksek hassasiyet göstermektedir. Matematiksel olarak STICH skoru daha hassastır, ancak aradaki fark klinik anlamda görmezden gelinebilir.

Anahtar Sözcükler: Serebral, hematom, hemoraji, hacim, mortalite, ROC.

Corresponding author: Mehmet Akif Topcuoglu, Prof. MD. Hacettepe University Hospitals, Department of Neurology and Neurological Intensive Care Unit, Ankara, TURKEY

Telephone: +903123051806 E-mail: matopcuoglu@yahoo.com

Received: 24.06.2019 Accepted: 29.07.2019

This article should be cited as following: Öge D.D, Arsava E.M, Pektezel M.Y, Kayım Yıldız Ö, Topçuoğlu M.A. Prediction of early prognosis in intracerebral hematomas: STICH-2 Prognosis score against Hemphill score. Turkish Journal of Cerebrovascular Diseases 2019; 25 (2): 106-112. doi: $10.5505 /$ tbdhd.2019.46320 
Öge et al.

\section{INTRODUCTION}

After ischemic heart disease, stroke is the second leading cause of death and the third leading cause of the disability-adjusted life year (DALYs) loss worldwide (1). Although ischemic stroke is the most prevalent stroke subtype, hemorrhagic stroke has a higher mortality and DALY burden, especially in middle and low-income countries $(1,2)$. A meta-analysis study showed that in intra-cerebral hemorrhage (ICH) patients, 1-year survival rate was $46 \%$, and 5-year survival rate was about $30 \%$ (3). Despite advances in neuroimaging and treatment strategies, these mortality rates didn't change much $(3,4)$. Therefore, it is still valid for the clinician to be able to predict the outcome of a patient presenting with spontaneous ICH.

In the setting of acute ICH prognostication, many tools and scoring systems have been created, each having acceptable accuracy to some extent (5). Among these scoring systems, one of the most accepted ones is "the ICH Score", published by Hemphill et al. in 2001 (6). This scoring system allows mortality risk stratification for ICH, and gives the clinician an idea about the outcome of the patient at the time of admission. On the other hand, in the STICH trial, researchers created an equation that gives the prognostic score of an $\mathrm{ICH}$ patient at presentation (7). This equation is used to dichotomize patient into a good prognosis group and a poor prognosis group.

The purpose of this study is to compare the prognostic yield of Hemphill's ICH Score and STICH Score.

\section{MATERIAL AND METHODS}

Patient Selection: The study is designed in a retrospective fashion. Using Hacettepe University Hospital Department of Neurology prospectively collected stroke database we identified patients admitted with ICH between 01.09.2009 and 01.09.2018. We extracted information from 307 patients. Among these, 31 patients were excluded due to incomplete data.

Data Acquisition: Collected data include demographic characteristics, Glasgow Coma Scale (GCS) at admission, National Institutes of Health (NIH) Stoke Scale at admission, known comorbidities, time interval from symptom onset to the first brain computed tomography (CT), time normalized ratio (INR) value at admission, hematoma location, hematoma volume on the initial and on the control CT, smoking, anti-platelet use, statin use and the length of stay in the hospital.

Hematoma location was divided into 8 groups: Lobar, putaminal, caudate, thalamic, cerebellar, pontine, undetermined locations and other locations. Comorbidities included hypertension (defined as Systolic Blood Pressure > $140 \mathrm{mmHg}$ and/or Diastolic Blood Pressure > 90mmHg), diabetes, hyperlipidemia (including hypercholesterolemia and hypertriglyceridemia), coronary artery disease, congestive heart failure, atrial fibrillation and rheumatic valve disease. Because of missing data on some of the patients about the amount of cigarettes they smoked, the patients' smoking habits was qualitatively evaluated. Hematoma volume was calculated using the " $\mathrm{AxBxC} / 2$ " method, where " $\mathrm{A}$ " is the greatest diameter of the largest hematoma slice, " $B$ " is the greatest hematoma diameter perpendicular to " $\mathrm{A}$ "; and " $C$ " is the numbers of the slices in which the hematoma is present multiplied by the slice thickness (all in cm) (8).

In-hospital length of stay was also determined. For those who have died, the inhospital length of stay was defined as the days the patient spent in the hospital until death.

Hemphill's ICH Score was calculated using the scoring system published in the original paper (Table) (6). And, the equation described (see below) in STICH trials for prognostication was calculated in all $(7,9)$.

Table. Hemphill's ICH score.

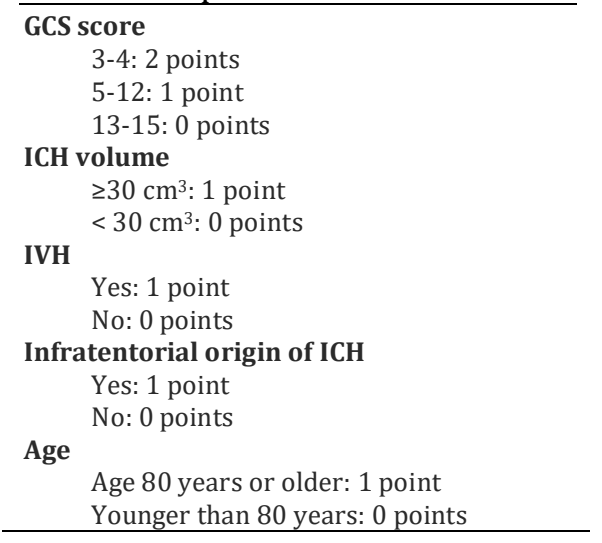




\section{Prognostic Score $=(10 \times$ admission GCS $)$-Age (years)-(0,64×Hematoma Volume $[\mathrm{mL}])$}

Statistical Analysis: The gathered data is transferred into SPSS v 21 for statistical analysis. For each prognostication method, we calculated its sensitivity, specificity, positive likelihood ratio and negative likelihood ratio concerning in-hospital mortality. We used receiver operating characteristic (ROC) curves to evaluate each method's accuracy. For each curve, their area under the curve (AUC) values are calculated and then analyzed to compare the ICH score versus the STICH prognostic score.

\section{RESULTS}

Clinical and Laboratory Descriptives of the Study Population: Among the 276 patients included in the study; $41 \%$ were female. The median age was $65 \pm 13$ years. Hematoma locations were: Lobar $34 \%$, thalamus $26 \%$, putamen $25 \%$, cerebellum $7 \%$, pontine $3 \%$, caudate $2 \%$, undetermined location $2 \%$ and other locations $1 \%$. The mean time elapsed between symptom onset and first brain CT was $259 \pm 239$ minutes (median \pm IQR: $179 \pm 218$ minutes). The meantime elapsed between the first CT and "control" CT was $1635 \pm 1530$ minutes (median \pm IQR: $2119 \pm 1528$ minutes). The mean ICH volume calculated on the first CTs was $32.8 \pm 36.9 \mathrm{cc}$. On the follow up CTs, the mean ICH volume was $35.1 \pm 37.5$ cc. The cohort's mean length of in-hospital stay (and/or day-to-death) was $23 \pm 33$ days (median $\pm I Q R$ : $10 \pm 20$ days).

Comorbidity rates at presentations were as follows: Hypertension $75 \%$, coronary artery disease $23 \%$, congestive heart failure $23 \%$, diabetes mellitus $21 \%$, hyperlipidemia $17 \%$, atrial fibrillation $8 \%$, rheumatic valve disease $2 \%$.Sixteen percent of the patients were active smokers at admission. The mean SBP at admission was $182 \pm 42 \mathrm{mmHg}$, the mean DBP at admission was $103 \pm 24 \mathrm{mmHg}$ and the mean heart rate at admission was $82 \pm 17 \mathrm{bpm}$. At presentation, the mean GCS was of $12 \pm 3$ points, and the mean NIHSS was of $13.4 \pm 10.8$ points.

Among the 276 patients, $34 \%$ were under at least one anti-platelet treatment, $32 \%$ were using acetylsalicylic acid (ASA) $(100 \mathrm{mg} /$ day) and $5.5 \%$ were using Clopidogrel $(75 \mathrm{mg} /$ day). $3.5 \%$ of the patients were on dual anti-platelet treatment composed of ASA $100 \mathrm{mg} /$ day with Clopidogrel 75 $\mathrm{mg} /$ day. The statin usage rate was $10 \%$.The coagulation parameters at admission were as follows: Mean INR: $1.33 \pm 1.02$; mean aPTT: $27.1 \pm 5$ sec. The mean platelet count was $220 \pm 70 \times 103 / \mu \mathrm{L}$.

Scores: For each patient, respective ICH scores and STICH scores were calculated using the scoring system and formula given in the Data Acquisition part $[6,7,9]$. For Hemphill's ICH score, the mean score was 1.4; the median score was 1 ; the IQR was of 2 and the standard derivation (SD) was of 1.3 for entire group. The mean Hemphill's ICH score was $2.66 \pm 1.22$ for the deceased patients and $1.27 \pm 1.12$ for ones who survived. For the STICH prognostic score, the average \pm SD was of $37.3 \pm 55$ and the median \pm IQR was of $53.8 \pm 55.4$ for the overall group. The mean score of SITCH score was $-21.23 \pm 64.64$ in deceased patients while it was $49.33 \pm 42.0$ in survivors. The association between the ICH score and the mortality rates with the association between the STICH score and the mortality rates are summarized in Figure I.

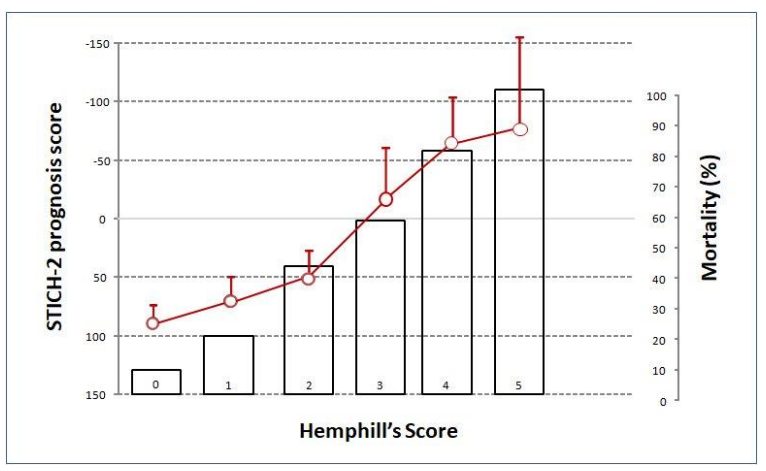

Figure I. Hemphill and STICH-2 scores and mortality rates.

ROC analysis: For Hemphill's ICH score, the ROC AUC was 0.791 (with 95\% Confidence Interval (CI) between 0.735 and 0.839 ). Using the ROC curve, we found the optimal cut-off value as 1 with a sensitivity of $83 \%$, specificity of $62 \%$, a positive likelihood ratio (+LR) of 2.2 and a negative likelihood ratio (-LR) of 0.28 . Four was the hundred percent specific cut-offs. For the STICH prognostic score, the ROC AUC is 0.829 (with $95 \%$ CI between 0.781 and 0.870 ). The optimal cutoff was determined as 36.61 with $80 \%$ sensitivity, $73 \%$ specificity, a +LR of 3.05 and a -LR of 0.27 . The cut-off value with the highest specificity $(100 \%)$ was $\leq-99.96$ (Figure II).The difference between the two methods' ROC AUC was 0.0277 (with 95\% CI between -0.0143 and 0.0696, $\mathrm{p}>0.05$ ) (Figure III). 


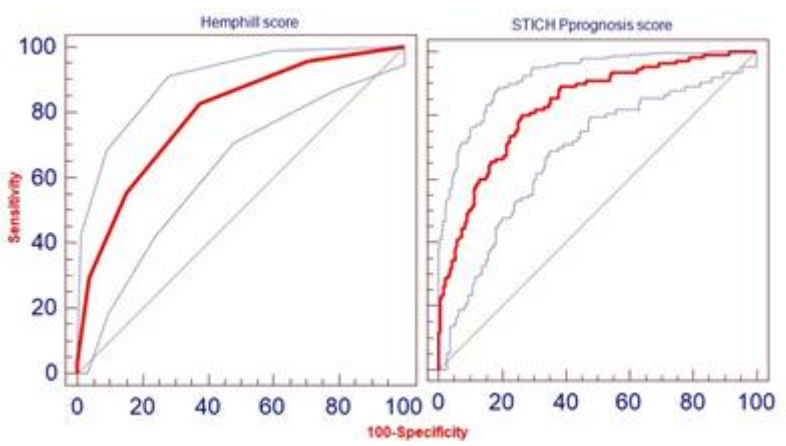

Figure II. Diagnostic performance based on ROC analysis graphs of Hemphill and STICH-2 scores for mortality prediction. Grey-broken lines represents $\pm 95 \%$ confidence intervals.

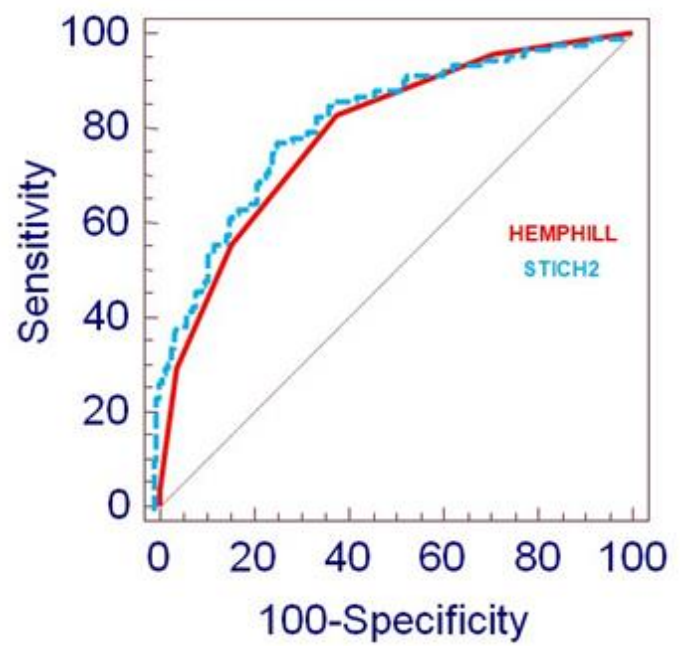

Figure III. Comparison of ROCs of Hemphill and STICH-2 scores.

\section{DISCUSSION}

With a 1-month fatality rate of $40 \%$, spontaneous ICH has a very poor prognosis. It has been reported in a meta-analysis that this fatality rate hasn't dropped in the past 30 years (4). In a clinical point of view, it is important to predict the patient's outcome in order to plan to what extend the treatment will persist. Thus, several prognostication tools have been described, each having some degree prognostication capabilities (5). A thorough literature screening has been made and its brief summary is given below.

Some of the prognostication tools use equations in order to predict the patient's outcome. Masè formula (10), Tuhrim equation (11), Grave Prognosis on Stage Score (GPoS) (12), the ICH index (ICHI) (13) and Get with the Guidelines Score (GWTG) (14) are in this group. Except ICHI, all of these formulas use exponential equations, making them hard to use on the bedside. Although ICHI seems to be more appropriate for clinical use, when adjusted to a cut-off value of 18 (the cut-off with the best performance), it shows a sensitivity of $65 \%$, which is low compared to the other equation based tools. The GWTG score stands out because it includes a wide variety of pre-ictal comorbidities, each having a different point on the scoring system. It also includes the hospital's healthcare service variability according to the admission time: the patient gets points if he/she doesn't arrive between 7AM and 5PM between Mondays and Fridays (14).

On the other hand, several point based scoring systems have been created for ICH outcome prediction. Among them, the most widely used is Hemphill's ICH score (A.K.A. Original ICH Score - oICH), which will be discussed later. Several modifications have been proposed for oICH. The Modified ICH score and the New ICH score was created by Cheung et al (15). Cheung's Modified ICH score differs from oICH by using NIHSS instead of GCS in the scoring system. The New ICH score is a completely different scoring system including NIHSS at admission, body temperature, pulse pressure, intraventricular extension and subarachnoid extension. Both showed better prognostic capabilities for good outcome then oICH. Another oICH modification was proposed by Godoy et al. (16): The Modified ICH A and B (mICH-A and mICH-B). These scores excluded the infra-tentorial hemorrhage item from the oICH's scoring system and stratified the intraventricular hemorrhage item using Graeb's score. They both showed similar mortality prediction powers to oICH, but they were superior in predicting good outcome. Another oICH modification is the ICH Grading Scale (ICH-GS) (17). It has the same criteria as oICH but their points and cut-offs are redistributed according to their impact on mortality. Thus, it has a higher sensitivity in predicting in-hospital mortality and 30 -day mortality $(78,2 \%$ and $78,5 \%$ respectively), and higher accuracy in predicting mortality and good functional outcome than oICH.

There are other point based scoring systems not derived from Hemphill's ICH score. The Essen ICH score proposed by Weimar et al. is based on the patient's age, NIHSS and NIHSS level of consciousness scale at admission (18). It is an examination based score and its prediction on 
complete recovery on Barthel Index (BI) after 100 days is found to be superior than the oICH and the modified ICH scores. The FUNC score differs from other scores by including pre-ictal cognitive impairment in the scoring system (19). Among these scores, the EDICH score is the only one including patient's INR at admission (20). Cho's Modified ICH score (MICH) was developed specifically for patients having basal ganglia hemorrhage (21) and the ICH outcome score (ICHOS) was developed specifically for hemodialysis patients (22). The Simplified ICH score (sICH) also takes the patient's hemodialysis dependency into account (23). The Landseed ICH score (LSICH), ICH functional outcome score (ICHFOS) and the Cincinnati Model are other prognostic tools that have proven good prognostic qualities (24-26).

For most of the scores mentioned above, the researchers compared their scores against Hemphill's ICH score. This underlines the importance of Hemphill's work, and constructs the basis of our study. In our study, we aim to compare Hemphill's ICH score and the STICH prognostic score. The oICH score was developed in 2001 by Hemphill et al. in an attempt to define a simple yet accurate predictive score that can be assessed at the time of presentation. The study was conducted in the University of California, San Francisco (UCSF). 152 patients were included in the study. The score was developed from the logistic regression model for the patients in the cohort. Five independent predictors were determined and they were assigned points according to their strength of association with outcome. These predictors are: GCS score (3-4: 2 points; 5-12: 1 point; 13-15: 0 point), ICH volume $(\geq 30 \mathrm{~cm} 3: 1$ point; $<30 \mathrm{~cm} 3$ : 0 point), intraventricular hematoma presence (yes: 1 point; no: 0 point), infra-tentorial origin of ICH (yes: 1 point; no: 0 point) and age ( $\geq 80$ : 1 point; $<80$ : 0 point) (Table). The original paper states that 30-day mortality of patients having $1,2,3,4$ and 5 points were $13 \%$, $26 \%, 72 \%, 97 \%$ and $100 \%$ respectively. No patient was given 6 points in the original cohort, but it was expected to be associated with a very high risk of mortality (6).

The STICH prognostic score was developed for outcome estimation in the original STICH trial. The patients' outcomes were assessed in 6 months after the event, and using the Glasgow Outcome Scale (GOS), they were categorized into ten categories: Good recovery (GR), moderate disability (MD), severe disability (SD), vegetative state (V) and dead (D), each having an upper and a lower subgroup (27). The given formula was then applied for each patient. The patients were dichotomized according to the median value: Those having an inferior score were grouped into the poor prognosis group, and those having a superior score were grouped into the good prognosis group. For the poor prognosis group, the patients that were classified as GR, MD and upper $\mathrm{SD}$ regarding to the GOSE were interpreted as having a favorable outcome. For the good prognosis group, the patients that were classified as GR and MD were interpreted as having a favorable outcome (7). The same method was used in the STICH II trial with a predefined cut-off value of 27.672 (this time using Extended Glasgow Outcome Scale-GOSE) (9). In the STICH II trial the prognostic score was divided into its quartiles and the patient count for each GOSE group was assorted to its associated quartile in order to construct a bar diagram. The diagram showed that as the prognostic score decreases, the number of the patients belonging to worse GOSE groups increases. This shows us that as the prognostic score decreases, the outcome becomes worse $(9$, 28).

In our study, we demonstrated that as the ICH score increases, the mortality increases, and as the STICH score decreases, the mortality increases (Figure I). These relationships are in parallel with the ones that were published in the original papers $(6,28)$. Using the ROC curves, we have determined that the optimal cut-off value for the ICH score was 1 (with a sensitivity of $83 \%$, a specificity of $62 \%$, a positive +LR of 2.20 and a -LR of 0.28 ) and the optimal cut-off value of STICH score was 36.61 (with a sensitivity of $80 \%$, a specificity of $73 \%$, a +LR of 3.05 and a -LR of 0.27 ). The value with $100 \%$ specificity was 4 for the ICH score and 99.96 for the STICH score.

Comparing the two methods' ROC curves, the AUC for STICH score's mortality prediction was slightly higher than the ICH score's ROC AUC ( 0.829 and 0.791 respectively). With such values, we can say that the two scoring systems are both useful and accurate in predicting in-hospital mortality. The difference between the two areas is calculated as 0,0277. Even though at first glance, the STICH score seems to be more accurate, the difference regarding accuracy between these two methods in predicting in-hospital mortality is not significantly different. 
There are some limitations in our study though. The study only comprised the survival data of the patients, and no functional outcome data was present for all the patients (due to lack of data uniformity). As the STICH score was defined in the original study according to the Extended Glasgow Outcome Scale, which itself is a functional outcome scale, we couldn't test the score's entire predictive accuracy. What we tested was the score's accuracy in predicting in-hospital mortality, which is included in the score's prediction scope, but doesn't represent the score's whole definition. Another point is that this study is a single center study and it is required to be replicated as a multi-center study to achieve greater significance.

An interesting point is that both methods use "GCS", "age" and "hematoma volume" as variables. Since both methods show similar predictive accuracies, one should question whether the "infratentorial hematoma location" and "intraventricular expansion" are truly independent predictors of outcome. In the FUNC score's paper, it was stated that intraventricular hematoma presence had no significant statistical impact on the functional outcome (19). This could be a tested in a further study.

Conclusion: In this study, we have compared Hemphill's ICH score against STICH score in order to find the most accurate in predicting in-hospital mortality in ICH patients. Even though at first glance, STICH score seems more accurate, the difference between these two methods' accuracies is negligible. Being a simple equation, the STICH score is a practical and accurate score for inhospital ICH related mortality prediction.

\section{REFERENCES}

1. Hankey, G.J., Stroke. The Lancet, 2017; 389(10069): 641654.

2. Krishnamurthi, R.V., et al., Global and regional burden of first-ever ischaemic and haemorrhagic stroke during 19902010: findings from the Global Burden of Disease Study 2010. The Lancet Global Health, 2013; 1(5): 259-281.

3. Poon, M.T., A.F. Fonville, and R. Al-Shahi Salman, Long-term prognosis after intracerebral haemorrhage: systematic review and meta-analysis. J NeurolNeurosurg Psychiatry, 2014; 85(6): 660-667.

4. van Asch, C.J., et al., Incidence, case fatality, and functional outcome of intracerebral haemorrhage over time, according to age, sex, and ethnic origin: a systematic review and meta-analysis. Lancet Neurol, 2010; 9(2): 167-176.

5. Satopaa, J., et al., Comparison of all 19 published prognostic scores for intracerebral hemorrhage. J Neurol Sci, 2017; 379: 103-108.

Turkish Journal of Cerebrovascular Diseases 2019; 25 (2): 106-112
6. Hemphill, J.C., 3rd, et al., The ICH score: a simple, reliable grading scale for intracerebral hemorrhage. Stroke, 2001; 32(4): 891-897.

7. Mendelow, A.D., et al., Early surgery versus initial conservative treatment in patients with spontaneous supratentorial intracerebral haematomas in the International Surgical Trial in Intracerebral Haemorrhage (STICH): a randomised trial. Lancet, 2005; 365(9457): 387397.

8. Kothari, R.U., et al., The ABCs of Measuring Intracerebral Hemorrhage Volumes. 1996; 27(8): 1304-1305.

9. Mendelow, A.D., et al., Early surgery versus initial conservative treatment in patients with spontaneous supratentorial lobar intracerebral haematomas (STICH II): a randomised trial. Lancet, 2013; 382(9890): 397-408.

10. Mase, G., et al., Immediate prognosis of primary intracerebral hemorrhage using an easy model for the prediction of survival. Acta NeurolScand, 1995; 91(4): 306309.

11. Tuhrim, S., et al., Volume of ventricular blood is an important determinant of outcome in supratentorial intracerebral hemorrhage.Crit Care Med, 1999; 27(3): 617621.

12. Poungvarin, N., et al., Grave prognosis on spontaneous intracerebral haemorrhage: GP on STAGE score. J Med Assoc Thai, 2006; 89 Suppl 5: S84-93.

13. Li, Y.F., et al., A new simple model for prediction of hospital mortality in patients with intracerebral hemorrhage. CNS NeurosciTher, 2012; 18(6): 482-486.

14. Smith, E.E., et al., A risk score for in-hospital death in patients admitted with ischemic or hemorrhagic stroke. J Am Heart Assoc, 2013; 2(1): e005207.

15. Cheung, R.T. and L.Y. Zou, Use of the original, modified, or new intracerebral hemorrhage score to predict mortality and morbidity after intracerebral hemorrhage. Stroke, 2003; 34(7): 1717-1722.

16. Godoy, D.A., G. Pinero, and M. Di Napoli, Predicting mortality in spontaneous intracerebral hemorrhage: can modification to original score improve the prediction? Stroke, 2006; 37(4): 1038-1044.

17. Ruiz-Sandoval, J.L., et al., Grading scale for prediction of outcome in primary intracerebral hemorrhages. Stroke, 2007; 38(5): 1641-1644.

18. Weimar, C., J. Benemann, and H.C. Diener, Development and validation of the Essen Intracerebral Haemorrhage Score. J NeurolNeurosurg Psychiatry, 2006; 77(5): 601-605.

19. Rost, N.S., et al., Prediction of functional outcome in patients with primary intracerebral hemorrhage: the FUNC score. Stroke, 2008; 39(8): 2304-2309.

20. Zis, P., et al., Predicting 30-day case fatality of primary inoperable intracerebral hemorrhage based on findings at the emergency department. 2014; 23(7): 1928-1933.

21. Cho, D.-Y., et al., A new modified intracerebral hemorrhage score for treatment decisions in basal ganglia hemorrhage-a randomized trial. 2008; 36(7): 2151-2156.

22. Huang, B.R., et al., Prognostic factors of spontaneous intracerebral haemorrhage in haemodialysis patients and predictors of 30-day mortality. 2008; 38(7): 568-574.

23. Chuang, Y.-C., et al., Risk stratification for predicting 30-day mortality of intracerebral hemorrhage. 2009; 21(6): 441447.

24. Chen, H.-S., et al., Risk factors of in-hospital mortality of intracerebral hemorrhage and comparison of ICH scores in a Taiwanese population. 2011; 66(1): 59-63. 
25. Ji, R., et al., A novel risk score to predict 1-year functional outcome after intracerebral hemorrhage and comparison with existing scores. 2013; 17(6): R275.

26. Broderick, J.P., et al., Volume of intracerebral hemorrhage. A powerful and easy-to-use predictor of 30-day mortality. 1993; 24(7): 987-993.
27. Mendelow, A., et al., Outcome assignment in the international surgical trial of intracerebral haemorrhage. 2003; 145(8): 679-681.

28. Gregson, B.A., et al., Update on the Surgical Trial in Lobar Intracerebral Haemorrhage (STICH II): statistical analysis plan. 2012; 13(1): 222. 